\title{
IMPACT OF REDUCING AND OXIDISING AGENTS ON THE WHEAT FLOUR DOUGH DYNAMIC RHEOLOGICAL PROPERTIES
}

\author{
P. Pečivová, V. Pavlínek, J. Hrabě, P. Valášek, L. Bouda
}

Received: April 2, 2010

\begin{abstract}
PEČIVOVÁ, P., PAVLÍNEK, V., HRABĚ, J., VALÁŠEK, P., BOUDA, L.: Impact of reducing and oxidising agents on the wheat flour dough dynamic rheological properties. Acta univ. agric. et silvic. Mendel. Brun., 2011, LIX, No. 1, pp. 191-198

Dynamic measurements with an oscillatory rheometer were made to study the rheological properties of wheat flour doughs and to examine how they are related to the composition of dough (the addition of oxidising and reducing agents).

It was found that L-cysteine hydrochloride monohydrate $\left(0.6 \times 10^{-2}-4.0 \times 10^{-2}\right.$ wt.\%), L-cysteine p. a. $\left(0.6 \times 10^{-2}-1.4 \times 10^{-2}\right.$ wt.\%) and glutathione-inactivated dry yeast $\left(1.8 \times 10^{-2}-14.0 \times 10^{-2}\right.$ wt.\%) show softening effects. An interesting phenomenon was observed from the concentration of $2.4 \times 10^{-2} \mathrm{wt}$.\% of L-cysteine p. a., where proces of weakening was decelerated. L-cysteine start making cystine by reaction of two cysteine molecules and proces of weakening was decelerated.

L-threonine, L-tryptophan within the concentration range of $2.0 \times 10^{-2}-14.0 \times 10^{-2} \mathrm{wt}$.\% and L-tyrosine, especially at concentrations $10.0 \times 10^{-2}-14.0 \times 10^{-2}$ wt.\%, have strengthening effects.

L-cysteine hydrochloride monohydrate exhibited the strongest softening effect while L-tryptophan had the strongest stiffening effect on the gluten network.

dough, amino acid, viscoelastic properties, flour
\end{abstract}

According to the continuous network model of protein structure (Bloksma and Bushuk, 1988), the elasticity of dough is at least partly due to disulfide crosslinks in the network of protein molecules (Bloksma and Bushuk, 1988). The rheological characterization of wheat flour doughs has been developed in the last few decades. Most researchers used the traditional dough-testing instruments such as a farinograph, an extensograph, or an alveograph. These studies have provided much practical information but they are limited to empirical correlations.

Alveoconsistograph, farinograph, extenzograph, mixograph have been used to measure rheological properties of doughs. Another method which is able to describe viscoelastic properties of doughs is dynamic oscillatory rheometry, which allows to monitor changes in tenacity and extensibility in doughs.

Determination the linear viscoelastic properties of gluten gels could provide the basis for evaluating of gluten quality based on a fundamental meas- urement of its inherent gluten network strength and viscosity (Lee and Mulvaney, 2003). The viscoelastic properties of wheat flour doughs have profound effects on dough machinability and the textural characteristics and keepability of the finished product (Uthayakumaran et al., 2000). Consequently, proper measurement of dough viscoelasticity with suited rheological techniques is of key importance to link the composition and structure of its raw material basic and added ingredients, additives and technological aids with the functionality of the dough in the bakery (Bloksma, 1990; Walker and Hazelton, 1996). As far as the linear range is concerned, dynamic tests allow a specific expression of well-defined rheological parameters, such as the storage modulus ( $\left.G^{\prime}\right)$, the loss modulus ( $G$ ") or their viscous counterparts ( $\eta$ " and $\left.\eta^{\prime}\right)$. In case of wheat flour dough, the problem of linearity has been discussed by several authors (Dreese et al., 1988; Attenburrow et al., 1990; Berland and Launay, 1995). 
Methods of small deformation dynamic rheology are often applied to study viscoelastic properties of wheat gluten. The results of these measurements are presented as mechanical spectra, i. e. curves representing the values of G' and G" as a function of angular frequency, $\left(G^{\prime}, G^{\prime \prime}=f(\omega)\right)$. The mechanical spectra are usually published and interpreted qualitatively in terms of 'G' and G" versus frequency without any further mathematical analysis (Bloksma, 1972; Popineau et al., 1994; Berland and Launay, 1995).

It is generally accepted that the rheological properties of dough and its three-dimensional network are dependent on the arrangement and number of disulfide bonds and sulfhydryl groups of protein (Dong and Hoseney, 1995).

Bloksma (1972) and Schofield et al. (1983) studied the relationship between the sulfhydryl and disulfide content of dough and its rheological properties. They reported that only small fractions of the total number of sulfhydryl and disulfide groups were rheologically effective, and these fractions were much smaller than the chemically reactive ones.

Disulfide bonds and gluten network can be modified by different additives such as reducing agents, oxidising agents etc., which are added to flour and influence the rheological properties of dough.

Reducing agents belong to dough conditioners used to improve extensibility and reduce mixing time. They are used to modify flour properties and to increase bakery throughput. Disulfide bonds in gluten can be broken by cysteine or glutathione-inactivated dry yeast as well as by mechanical mixing.

Reducing agents include e.g. L-cysteine p. a., L-cysteine hydrochloride monohydrate and glutathione-inactivated dry yeast. Cysteine is the most commonly used reducing agent in bread. It is an amino acid that is usually produced synthetically as L-cysteine hydrochloride. Glutathione-inactivated dry yeast is a tripeptide that contains cysteine but is not generally available in its pure form. It functions similarly to L-cysteine but it is potentially more effective because it can react more times. The addition of glutathione-inactivated dry yeast to flour-water dough reduces $G^{\prime}$ and increases the loss tangent (tan ס). The doughs become relatively less elastic (Dong and Hoseney, 1995). Glutathione-inactivated dry yeast also contains two negatively charged carboxylate groups and one positively charged amino group. Obviously, these functional groups may interact with the charged residues of proteins. However, the most reactive group in glutathione is sulfhydryl of the cysteine side chain. This group can serve as a nucleophile, reductant, and scavenger of free radicals. Reactions involving glutathione-inactivated dry yeast as a reductant usually lead to the formation of glutathione-inactivated dry yeast disulfide.

G' is expected to increase with the increasing number of disulfide bonds in gluten and G" is expected to increase with the increasing content of low molecular sulfhydryl. The presence of glutathioneinactivated dry yeast increases the rate of thiol-di- sulfide interchange reactions, which decreases the size of large proteins and results in lower molecular weight. Therefore, the added glutathione-inactivated dry yeast has a better chance of reacting with low molecular weight sulfhydryl groups to form a stable disulfide bond. This can be viewed as free radical scavenging. As a result, it reduces the chance of intermolecular cross-links (Dong and Hoseney, 1995).

Sensitivity of the rheological properties of dough to oxidation or reduction suggests that disulfide bonds play a major role in dough rheology. Dough rheology is connected with gluten structure, and several models have been proposed to describe it (Skerritt et al., 1999a; 1999b; Wieser, 2007).

On the other hand, it is known that oxidising agents are able to strengthen the gluten network in dough by uncovalent bonds. Doughs are more cohesive and stiffened. These doughs and bakery products made from them have a bigger volume and better porosity.

The glutenin proteins subunits are tyrosine-rich, and these amino acids could participate in the formation of covalent bonds, putatively involving tyrosyl residues in crosslinks catalyzed by one or more peroxidases (Belli et al., 2003; Held et al., 2004). Dityrosine also occurs in wheat flours and doughs, perhaps acting as a kind of stabilizing crosslink in the wheat gluten structure in addition to those provided by disulfide bonds (Tilley et al., 2001). It is usual to add oxidising agents to doughs during mixing and baking. These compounds oxidize and modify certain amino acids and could influence the structure of polymers, promoting their capacity to form aggregates and increasing the elasticity of the gluten. Dityrosines and isodityrosines are products of tyrosine oxidation. Thus, intramolecular and intermolecular crosslinked tyrosine might contribute to the structure of the gluten network (Pena et al., 2006).

The aim of this study is to analyze the effect of amino acids as L-threonine and L-tryptophan, which are normally present in minor amount in wheat flour, on the rheological properties of dough and to determine wheather the amino acids such as L-threonine and L-tryptophan influence the rheology of dough as oxidising or reducing agents. These amino acids belong to essential amino acids and their addition to the dough strengthen final bakery product thereby improve their quality (nutritional value).

\section{MATERIALS AND METHODS}

\section{Materials and dough preparation}

White wheat flour (moisture 14.3\%, wet gluten in dry matter $36.4 \%$, falling number 339 s) provided by Penam, Kroměříž, Czech Republic (Pečivová et al., 2008; Pečivová et al., 2010) was used. With all relative matter content expressed on the basis of moist flour or total dough weight, unless otherwise stated, doughs were composed of flour, redistiled water 
and salt. They were mixed for 5.5 minutes in a spiral kneader Bosch Profi Mixx 47 MUM 4770/05 (Robert Bosch Hausgeraete GmbH, Germany).

Reducing agents as L-cysteine p. a. (Merck KGaA, Darmstadt, Germany), L-cysteine hydrochloride monohydrate (Ireks GmbH, Eppelborn, Germany) within the concentration range of $0.6 \times 10^{-2}-4.0 \times$ $10^{-2}$ wt.\%, glutathione-inactivated dry yeast (glutathione content is specified as 15-20 mg per $1 \mathrm{~g}$ of flour) from Ireks GmbH, Eppelborn, Germany $\left(1.8 \times 10^{-2}\right.$ - $14.0 \times 10^{-2}$ wt.\%), oxidising agent as L-tyrosine and other two amino acids as L-threonine, L-tryptophan (Merck KGaA, Darmstadt, Germany) within the concentration range of $2.0 \times 10^{-2}-14.0 \times 10^{-2} \mathrm{wt}$.\% were added in order to modify dough properties. Concentrations of used amino acids were chosen by their chemical power to influence or change the gluten network.

Before testing, doughs were stored for 50 minutes in a small tight box at room temperature to allow the stresses developed during mixing to relax.

\section{Equipment for rheological measurements}

The rotational viscometer Bohlin Gemini (Malvern Instruments, UK) at a temperature of $(25 \pm 1)^{\circ} \mathrm{C}$ with parallel plate geometry was used. The gap was set at $1.5 \mathrm{~mm}$ and the diameter of parallel plates was $25 \mathrm{~mm}$. Before the measurement, the dough sample was left to stand for 5 minutes to allow the induced stresses to relax. The measurements were performed within the area of linear viscoelasticity with a constant stress of $50 \mathrm{~Pa}$. The surface of plates was covered by sandpaper to avoid any slippage problem. The dough edges were cut and coated with sili- cone oil to prevent moisture loss. Presented results are obtained from 3 replicants.

\section{RESULTS AND DISCUSSION}

The changes of G' and G" moduli of doughs with L-cysteine hydrochloride monohydrate, L-cysteine p. a. and glutathione-inactivated dry yeast are described in Fig. 1. As can be seen, G' and G" moduli of glutathione-inactivated dry yeast and L-cysteine hydrochloride monohydrate were lower than those of the control dough. In both cases, G' decreased more rapidly than G". This dependence shows that L-cysteine hydrochloride monohydrate is a stronger reducing agent than glutathione-inactivated dry yeast. It is worth noting that the concentration of glutathione-inactivated dry yeast was 10 times higher than that of L-cysteine hydrochloride monohydrate and thus their reducing effects could be compared. On the other hand, L-cysteine p. a. showed a different tendency. G' had the same trend as the control dough up to the angular frequency of $1 \mathrm{rad} / \mathrm{s}$, but then it became higher than that of the control dough. G" was higher than that in the control dough within the whole angular frequency range. It means that the mechanism of L-cysteine p. a. activity is different and will be explained later in figure 2.

Fig. 2 shows the changes of G' and G" dependence on the concentration of L-cysteine p. a. As can be seen, G' and G" were lower than those of the control dough up to the concentration of $1.4 \times 10^{-2}$ wt.\% but then they became higher from the concentration of $2.4 \times 10^{-2}$ wt.\%. This finding corresponds with recent results in the studies by (Elkhalifa and El Tinay, 2002; Angioloni and Dalla Rosa, 2007) who in-

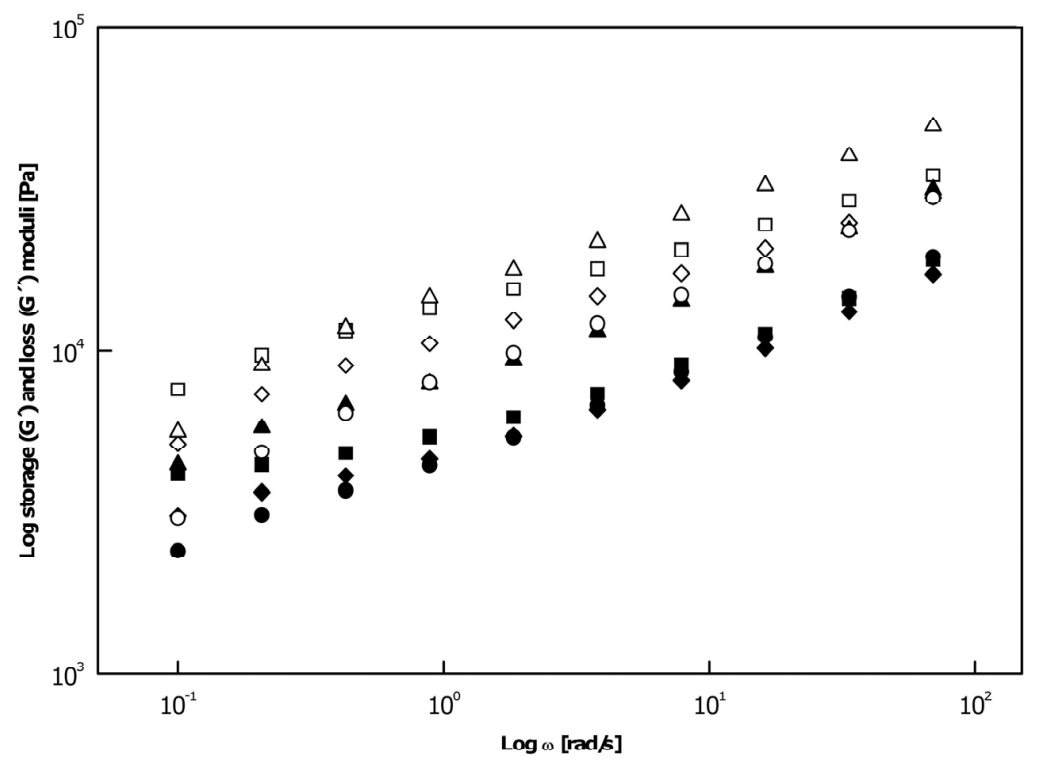

1: Dependence of storage (G') (open symbols) and loss (G') (solid symbols) moduli on the angular frequency $(\omega)$ in the control dough (open square, solid square) and dough with different reducing agents such as glutathione-inactivated dry yeast (open diamond, solid diamond), L-cystein p.a. (open triangle, solid triangle) and L-cysteine hydrochloride monohydrate (open circle, solid circle). Concentration of additives: $3.2 \times 10^{-2} w t . \%$ 


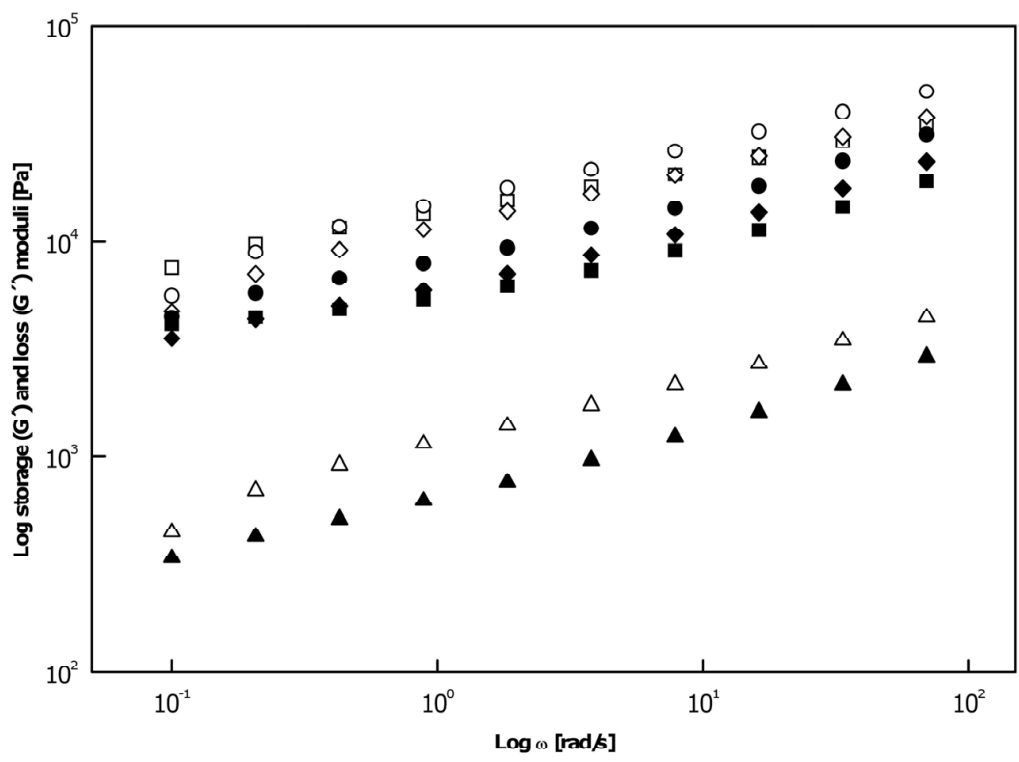

2: Dependence of storage (G') (open symbols) and loss (G') (solid symbols) moduli on the angularfrequency $(\omega)$ in the control dough (open square, solid square) and dough with L-cysteine p. a. at the concentrations of $1.4 \times 10^{-2} \mathrm{wt}$.\% (open triangle, solid triangle), $2.4 \times 10^{-2} \% \mathrm{wt}$. (open diamond, solid diamond), $3.2 \times 10^{-2} \mathrm{wt}$.\% (open circle, solid circle)

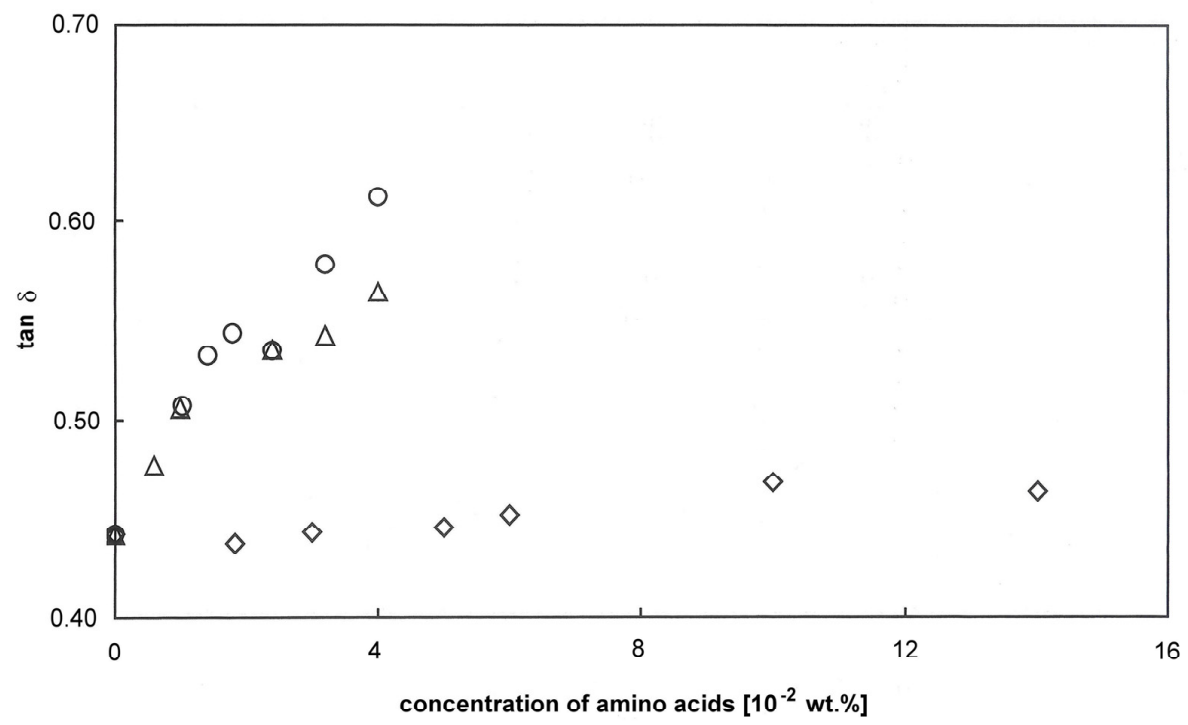

3: Dependence of loss tangent (tan $\delta=G^{\prime \prime} / G^{\prime}$ ) on the concentration of L-cysteine hydrochloride monohydrate (open circle), L-cysteine p. a. (open triangle) and glutathione-inactivated dry yeast (open diamond) at the angular frequency $\omega=1 \mathrm{rad} / \mathrm{s}$

vestigated the reduction abilities of cysteine in low concentrations. They found that cysteine behaves as a strong reducing agent in very low concentrations (in hundredths of percent).

However, it was impossible to measure the rheological properties of cysteine at higher concentrations using e. g. an alveograph or consistograph because these doughs became stuck on the sensors. On the other hand, dynamic oscillatory rheometry allows to measure doughs containing higher concentrations of cysteine (in tenths of percentage). L-cysteine p. a. creates disulphide bonds from cysteine in proteins at higher and middle concentrations. Therefore we suppose that sulphur might be blocked by L-cysteine molecule and unable to create the disulphide bond with the second chain of proteins. L-cysteine p. a. begins to behave differently in high concentrations than one might expect. L-cysteine should start making cystine by reaction of two cysteine molecule and proces of weakening is decelerated. The investigation of forming cystine from L-cysteine in dough will be continued in other part of our research. 


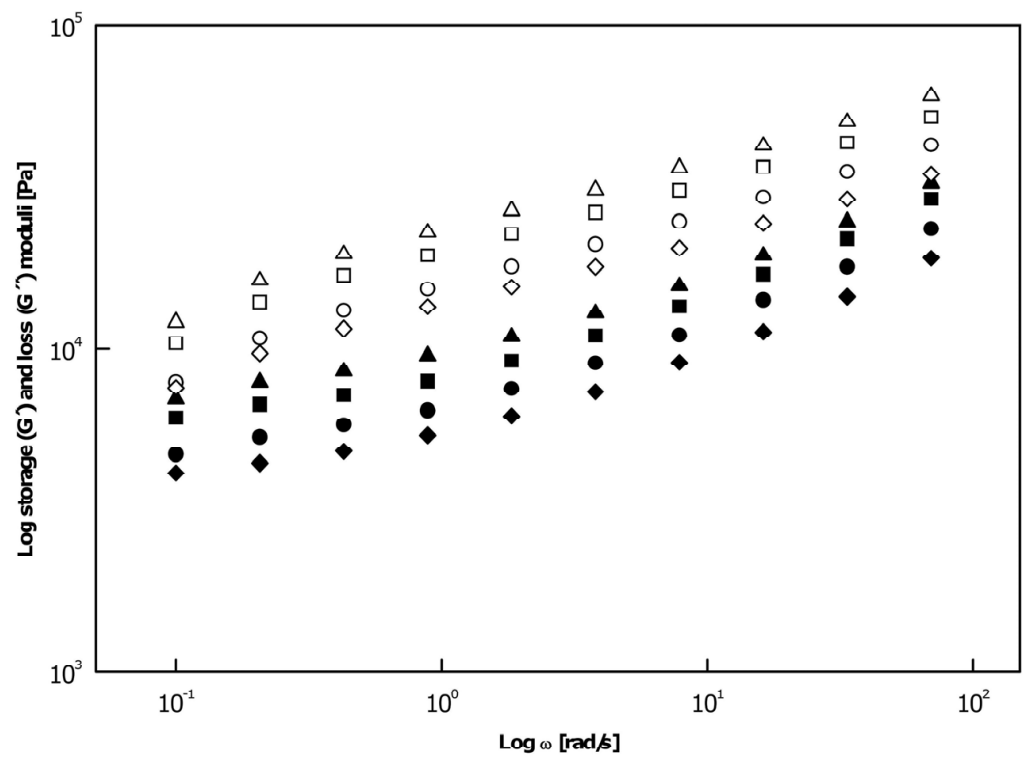

4: Dependence of storage (G') (open symbols) and loss (G') (solid symbols) moduli on the angular frequency $(\omega)$ in the control dough (open diamond, solid diamond) and dough with different oxidising agents such as L-threonine (open square, solid square), L-tryptophan (open triangle, solid triangle) and L-tyrosine (open circle, solid circle). Concentration of additives: $14.0 \times 10^{-2} \mathrm{wt} . \%$

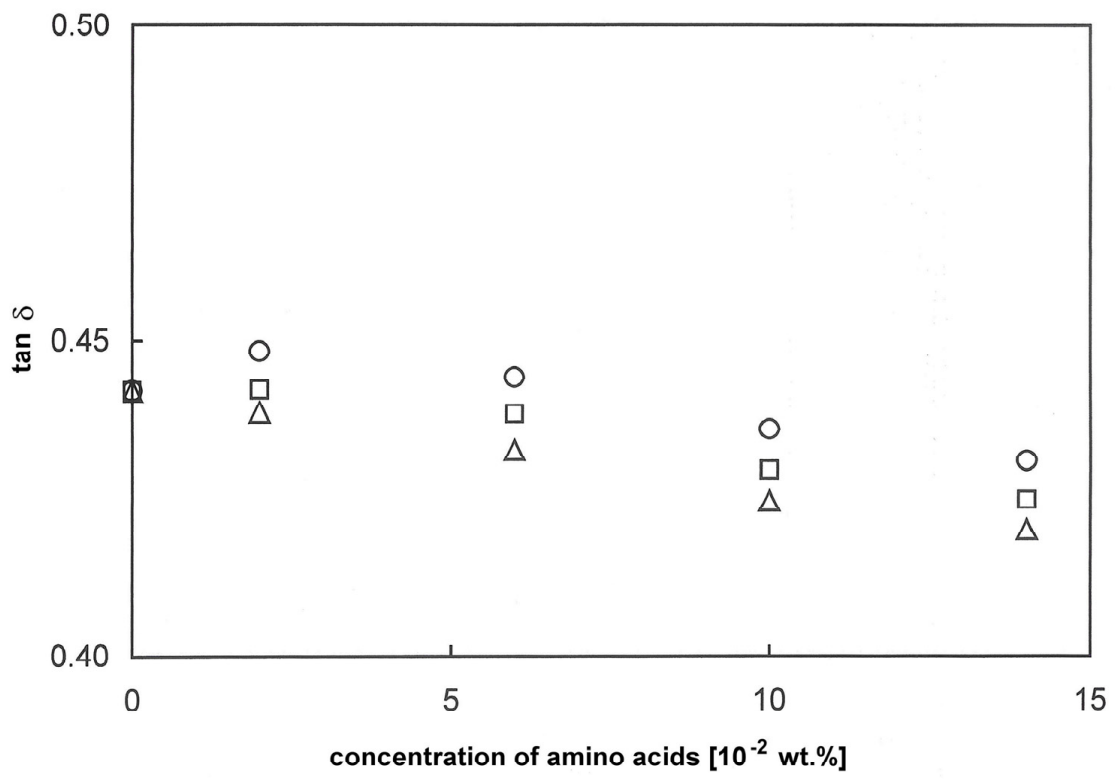

5: Dependence of loss tangent ( $\left.\tan \delta=G^{\prime \prime} / G^{\prime}\right)$ on the concentration of L-threonine (open square), $L$-tryptophan (open triangle) and L-tyrosine (open circle) at the angular frequency $\omega=1 \mathrm{rad} / \mathrm{s}$.

Different reducing effects of the individual amino acids such as L-cysteine hydrochloride monohydrate, glutathione-inactivated dry yeast and Lcysteine p. a. are shown in fig. 3. As can be seen, the curves of dough with L-cysteine hydrochloride monohydrate and L-cysteine p. a. increased more than those with glutathione-inactivated dry yeast. The additions of L-cysteine p. a. and L-cysteine hydrochloride monohydrate showed almost the same influence on softening of the dough whereas the curve of the dough with glutathione-inactivated dry yeast showed a relatively weak effect (it is a weak reducing agent which breaks disulphide bonds much more slowlier). That means that L-cysteine hydrochloride monohydrate was the strongest reducing agent. The influence of L-cysteine was investigated in study (Lee and Mulvaney, 2003) who found that addition of L-cysteine reduces the effective degree of cross-linking in gluten such that the reversible gel network was completely eliminated at $25^{\circ} \mathrm{C}$.

Fig. 4 shows small differences in the oxidising effect between the doughs with additives such as 
L-tryptophan, L-tyrosine and L-threonine within the whole frequency range. It can be seen that both G' and G" moduli increased slightly in comparison with the control dough. L-tryptophan had the strongest stiffening effect, while L-tyrosine had the least noticeable effect. We suppose that L-tyrosine, L-threonine and L-tryptophan cause stiffening of the gluten structure and L-tryptophan and L-threonine are able to form more uncovalent hydrogen bonds or increase the abilities to strengthen the gluten structure by forming these hydrogen bonds from dithirosine which is forming by oxidation during relaxation of the dough. Dithirosine and isodityrosines as products of tyrosine oxidation have recently been investigated by Pena et al. (2006).

Fig. 5 shows the dependence of $\tan \delta$ on the concentrations of oxidising agents. There can be seen a small difference between the oxidising effect of additives such as L-tryptophan, L-tyrosine and L-threonine on doughs. Tan $\delta$ has the same trend in all doughs with oxidising agents. In all concentrations, L-threonine and L-tryptophan were able to stiffen the dough slightly. L-tryptophan had a stronger effect on strengthening the dough. L-tyrosine was the weakest oxidising agent and stiffened the dough only at concentrations higher than $10.0 \times$ $10^{-2}$ wt.\%.

\section{CONCLUSION}

According to the results obtained by the dynamic oscillatory rheometry it was found that L-cysteine hydrochloride monohydrate was the strongest reducing agent from the amino acids studied. It was also found that at low concentrations L-cysteine p. a. behaved like L-cysteine hydrochloride mono- hydrate but at higher concentrations its reducing ability became weaker. On the other hand, L-tryptophan had the strongest stiffening effect within the amino acids examined compared to the oxidising agents such as L-threonine and L-tyrosine. L-threonine and L-tryptophan are amino acids which are normally present in minor amount in wheat flour. These amino acids belong to essential amino acids and their addition to the dough strengthen final bakery product thereby improve their quality (nutritional value). L-tyrosine showed the least noticeable effect on the elasticity and viscosity of the dough.

Generally, the impact of reducing and oxidising agents on flour rheology is different. L-tyrosine, L-threonine and L-tryptophan are relatively weak oxidising agents and their stiffening effects were not so strong as the softening effects of the reducing agents, especially that of L-cysteine hydrochloride monohydrate.

\section{Practical applications}

Additives such as amino acids are daily used in bakery industry but L-threonine and L-tryptophan have not been used for modification of viscoelastic properties of the wheat flour dough yet. These additives are amino acids which are normally present in wheat flour but in minor amount and their addition has also positive nutritional effects. Reducing agents such as glutathione-inactivated dry yeast, L-cysteine p. a. and L-cysteine hydrochloride monohydrate in low concentrations and oxidising agents as L-tyrosin were used for comparison too. Furthermore, all additives were added to doughs for bakery experiments. These experiments had the positive impact on quality of final bakery products.

\section{SUMMARY}

Influence of oxidising and reducing agents was measured by the oscillatory rheometer. The oscillatory rheometer allow to measure higher concentration (amount) of additives, especially reducing agents. Reducing agent, L-cysteine hydrochloride monohydrate was the strongest reducing agent. L-cysteine p. a. behaved like L-cysteine hydrochloride monohydrate at low concentrations but at higher concentrations its reducing ability was weaker. Oxidising agent, L-tryptophan had the strongest stiffening effect. On the other hand, L-tyrosine showed the least noticeable effect on the elasticity and viscosity of the dough.

This work was kindly supported by a project of Czech Ministry of Education, Youth and Sports (Grant No. MSM 7088352101).

An alphabetical list of abbreviations

Appendix

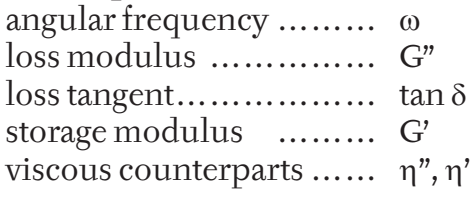




\section{REFERENCES}

ANGIOLONI, A., DALLA ROSA, M., 2007: Effects of cysteine and mixing conditions on white/whole dough rheological properties. Journal of Food Engineering, 80: 18-23. ISSN 0260-8774.

ATTENBURROW, G., BARNES, D. J., DAVIES, A. P., INGMAN, S. J., 1990: Rheological properties of wheat gluten. Journal of Cereal Science, 12: 1-14. ISSN 0733-5210.

BELLI, S. I., WALLACH, M. G., LUXFORD, C., DAVIES, M. J., SMITH, N. C., 2003: Roles of tyrosinerich precursor glycoproteins and dityrosine- and 3,4-dihydroxyphenylalanine-mediated protein crosslinking in development of the oocyst wall in the coccidian parasite Eimeria maxima. Eukaryotic Cell, 2: 456-464. ISSN 1535-9778.

BERLAND, S., LAUNAY, B., 1995: Rheological properties of wheat flour doughs in steady and dynamic shear: effect of water content and some additives. Cereal Chemistry, 72: 48-52. ISSN 0009-0352.

BLOKSMA, A. H., 1972: The relation between the thiol and disulfide contents of dough and its rheological properties. Cereal Chemistry, 49: 104-118. ISSN 0009-0352.

BLOKSMA, A. H., 1990: Rheology of the breadmaking process. Cereal Foods World, 35: 228-236. ISSN 0146-6283.

BLOKSMA, A. H., BUSHUK, W., 1988: Rheology and chemistry of dough. In: Wheat chemistry and technology, ed. by Pomeranz Y, American Association of Cereal Chemistry, USA, 131-132.

DONG, W., HOSENEY, R. C., 1995: Effects of certain breadmaking oxidants and reducing agents on dough rheological properties. Cereal Chemistry, 72: 58-64. ISSN 0009-0352.

DREESE, P. C., FAUBION, J. M., HOSENEY, R. C., 1988: Dynamic rheological properties of flour, gluten, and gluten-starch doughs. II. Effect of various processing and ingredient changes. Cereal Chemistry, 65: 354-359. ISSN 0009-0352.

ELKHALIFA, A. E. O., EL-TINAY, A. H., 2002: Effect of cysteine on bakery products from wheatsorghum blends. Food Chemistry, 77: 133-137. ISSN 0308-8146.

HELD, M. A., TAN, L., KAMYAB, A., HARE, M., SHPAK, E., KIELISZEWSKI, M. J., 2004: Di-isodityrosine is the intermolecular crosslink of isodityrosine-rich extensin analogs crosslinked in vitro. Journal of Biological Chemistry, 279: 55474-55482. ISSN 0021-9258.

LEE, C. C., MULVANEY, S. J., 2003: Dynamic viscoelastic and tensile properties of gluten and glutenin gels of common wheats of different strength. Journal of Agricultural and Food Chemistry, 51: 23172327. ISSN 0021-8561.
PEČIVOVÁ, P., BUREŠOVÁ, I., HRABĚ, J., KRÁČMAR, S., 2008: The influence of reducing and oxidising agents on the rheology of wheat flour dough. Acta universitatis agriculturae et silviculturae Mendelianae Brunensis, 56: 163-170. ISSN 1211-8516.

PEČIVOVÁ, P., BUREŠOVÁ, I., HRABĚ, J., 2010: Changes of protein fractions in wheat flour caused by additives. Acta universitatis agriculturae et silviculturae Mendelianae Brunensis, 58: 123-130. ISSN 1211-8516.

PENA, E., BERNARDO, A., SOLER, C., JOUVE, N., 2006: Do tyrosine crosslinks contribute to the formation of the gluten network in common wheat (Triticum aestivum L.) dough. Journal of Cereal Science, 44: 144-153. ISSN 0733-5210.

POPINEAU, Y., CORNEC, M., LEFEBVRE, J., MARCHYLO, B., 1994: Physical-chemical characterisation of glutens and gluten subfractions of near isogenic lines of wheat "Sicco": influence of HMW glutenin subunits on the glutenin polymerisation and on rheological properties of glutens. Journal of Cereal Science, 19: 231-241. ISSN 0733-5210.

SCHOFIELD, J. D., BOTTOMLEY, R. C., TIMMS, M. F., BOOTH, M. R., 1983: The effect of heat on wheat gluten and the involvement of sulphydryldisulphide interchange reactions. Journal of Cereal Science, 1: 241-253. ISSN 0733-5210.

SKERRITT, J. H., HAC, L., BEKES, F., 1999a: Depolymerisation of the gluten macropolymer during dough mixing. 1. Changes in levels, molecular weight distribution and overall composition. Cereal Chemistry, 76: 395-401. ISSN 0009-0352.

SKERRITT, J. H., HAC, L., LINDSAY, M. P., BEKES, F., 1999b: Depolymerisation of the gluten macropolymer during mixing. 2. Differences in the retention of specific glutenin subunits. Cereal Chemistry, 76: 402-409. ISSN 0009-0352.

TILLEY, K. A., BENJAMIN, R. F., BAGOROGOZA, K. E., OKOT-KOTBER, B. M., PRAKASH, O., KWEN, H., 2001: Tyrosine crosslinks: Molecular basis of gluten structure and function. Journal of Agricultural and Food Chemistry, 49: 2627-2632. ISSN 0021-8561.

UTHAYAKUMARAN, S., NEWBERRY, M., KEENTOK, M., STODDARD, F. L., BEKES, F., 2000: Basic rheology of bread dough with modified protein content and glutenin-to-gliadin ratios. Cereal Chemistry, 77: 744-749. ISSN 0009-0352.

WALKER, C. E., HAZELTON, J. L., 1996: Dough rheological tests. Cereal Foods World, 41: 23-28. ISSN 0146-6283.

WIESER, H., 2007: Chemistry of gluten proteins. Food Microbiology, 24: 115-119. ISSN 0740-0020.

\section{Address}

Ing. Pavlína Pečivová, Ph.D., doc. Ing. Jan Hrabě, Ph.D., Bc. Lubomír Bouda, Ústav technologie a mikrobiologie potravin, Ing. Pavel Valášek, CSc., Ústav biochemie a analýzy potravin, doc. Dr. Ing. Vladimír Pavlínek, Centrum polymerních materiálů, Fakulta technologická, Univerzita Tomáše Bati ve Zlíně, nám. T. G. Masaryka, 275, 76272 Zlín, Česká republika. e-mail: pecivova@ft.utb.cz 
